\title{
Compartilhamento do comum
}

\author{
Uso compartido común
}

\author{
Common Sharing
}

\section{Juliana Porto Machado ${ }^{1}$}

\begin{abstract}
Resumo
Este artigo tem como objetivo discorrer sobre as redes de compartilhamento comum existente na transmissão de saberes por meio das memórias. Para tanto utilizará da concepção de memória individual e/ou coletiva, em meio em um discurso de interpretação dos sóciotransmissores. Com foco no objeto dessa pesquisa a metodologia utilizada para realizar o proposto neste trabalho foi pesquisa qualitativa do tipo descritiva com foco em análise documental. Utilizando como arcabouço autores que trabalham com os conceitos analisados. Em que ação do compartilhamento comum pode ser compreendida como a partilha de ideias, noções, conceitos, signos e experiências coerentes e fortemente organizadas do indivíduo com sua coletividade. Sendo, um processo continuo, não é apenas a ação de um indivíduo transmitir o que conhece para outro, não é algo linear, já que o passado não é uma imagem pronta no presente e que pode ser completamente rememorado.
\end{abstract}

Palavras-Chave: Compartilhamento comum; Memória; Tradição; Sóciotransmissores

\section{Resumen}

Este artículo se diseña como objetivo discorde sobre como redes de compartimiento de datos existentes en la transmisión de los recursos por meio las memorias. Para tanto utilizar la concepción individual de la memoria y / o coletiva, em meio em to speech de interpretation of sóciotransmissores. Com foco no objeto dessa pesquisa a metodologia Utilizado para realizar o proponer un nuevo trabajo para la calidad del producto descriptivo con foco en el análisis documental. Utilizando como arcabuco los autores que trabalham con los enfoques analisados. Que em Ação hacer compartilhamento comum pode ser compreendida Como un Partilha de Ideias, noções, CONCEITOS, signos e EXPERIENCIAS coerentes e fortemente ORGANIZADAS hacer indivíduo coletividade com sua. Sendo a processo continuo, não é Apenas un Ação de um indivíduo transmitir O que conhece párrafo outro, não é algo lineal, já que o passado não é uma imagem Pronta sin Presente e Que pode ser completamente rememorado.

Palavras-Chave: Compartilhamento comum; Memória; tradição; Sóciotransmissores

\begin{abstract}
This article aims to discuss the common networks of sharing in the transmission of knowledge through the memories. In order to do so, it will use the concept of individual and / or collective memory, in the midst of a speech of interpretation of the transceivers. Focusing on the object of this research the methodology used to accomplish the proposed in this work was qualitative research of the descriptive type focusing on documentary analysis. Using as framework authors working with the concepts analyzed. In what action of common sharing can be understood as the sharing of coherent and strongly organized ideas, notions, concepts, signs, and experiences of the individual with his or her collectivity. Being a continuous process, it is not only the action of an individual to transmit what he knows to another, it is not something linear, since the past is not an image ready in the present and can be completely recalled.
\end{abstract}

Keywords: Common share; Memory; Tradition; Transceivers

\footnotetext{
${ }^{1}$ Mestranda no Programa de Pós-Graduação em Memória Social e Patrimônio Cultural, pela Universidade Federal de Pelotas (UFPEL). Julianamachado209@gmail.com
} 


\section{Introdução}

Este artigo irá discorrer sobre as definições e contradições da memória enquanto classificada como coletiva ou individual, partindo da visão de autores conceituados em sua área de investigação. Na formação das redes de compartilhamentos e efetivação de um comum transmitido entre os sujeitos socioculturais de um grupo.

Logo, existem memórias que se manifestam automaticamente, que não exigem um exercício forte de evocação são: os hábitos, os gestos e a linguagem corporal/oral/escrita, em que não precisa realizar-se uma reflexão analítica, é automática, o passado apropriasse do corpo como local de ação sendo categorizada por Candau (2011) como um protomemoria.

Para o autor em sua classificação da memória temos também a memória propriamente dita ou de evocação, como reflexos da cultura, parte do recordar voluntariamente, do querer lembrar, pela "evocação deliberada ou invocação involuntária de lembranças autobiográficas, ou pertencentes a uma memória enciclopédia" (p. 23).

Já a metamemória pelo autor supracitado, é elemento primordial para a construção identitárias seja individual ou coletiva, e a forma como o sujeito interpreta as lembranças recordadas e as reivindica. $\mathrm{O}$ conhecimento e reconhecimento que se tem dessas, a representação que faz de sua própria memória em relação de troca com o seu passado. O discurso e postura que cada sujeito tem de suas memorias pessoais.

No caso, ao comunicarmos nossas memórias para outros estamos utilizando a metamemoria, a ideia de patrimônio é um exemplo dessa forma memorial. Assim, a metamemoria transmite uma narrativa de crenças comuns para as memorias individuais, ou seja, a única memória que pode ser compartilhada. Então, metamemoria é a única possibilidade de uma memória coletiva.

Como declara o autor a memória pode ser entendida como uma reinterpretação e modificação contínua e atualizada do passado, vai além de uma retransmissão do passado completo e intacto. E a possibilidade de uma memória coletiva só poderá acontecer através da metamemoria, em um discurso de que membros de um grupo irão produzir a cerca de uma memória supostamente comum e reconhecida por todos.

Dessa forma, ele, trata das metáforas de memórias compartilhadas, que não possuem teor empírico, considerando apenas alguns elementos socioculturais. Porém, não há como nos desprendermos dos efeitos das generalizações, já que esses transmitem de certa forma fatos da realidade. Para tanto, Candau afirma que "só podemos compreender a ideia de memória coletiva a partir da noção de retóricas holistas". Ou seja, a partir de certas generalizações, de termos, de códigos, de imagens, de gestos, de hábitos que construiriam uma ilusão de 
estabilidade homogênea de lembranças compartilhadas. "Um reagrupamento de indivíduos (a comunidade, a sociedade, o povo) [...] representações, crenças, recordações (ideologia X ou Y, a religião popular, a consciência ou a memória coletiva) ou ainda elementos imaginários (identidade étnica, identidade cultural)" (p. 29).

Essa forma de coletividade de uma memória não abarca todos os aspectos da realidade social observada. A memória individual se perde, não teríamos necessidade de identidades pessoais apenas compartilhadas, o eu e outro seriamos TODOS em uma visão de conjunto e de grupo homogêneo, as memórias seriam as mesmas, não havendo espaço para o discurso da diversidade cultural.

\section{Memória Coletiva e/ou Individual}

Parte-se da visão da memória na perspectiva individual, já que compreende que essa seria a única que se pode comprovar. Para tal posicionamento explica que o discurso de memória coletiva é uma representação, uma expressão da metamemoria, um discurso reproduzido sobre uma suposta memória comum e compartilhada como todos os sujeitos que compõem um grupo social. Como exemplo: a memória coletiva de uma reunião familiar, todos teriam ilusoriamente a sensação de compartilharem uma lembrança comum a todos sob tal ação.

No entanto, para Halbwachs (2004) só possuímos lembranças se nos apoiarmos nas recordações dos outros, e se estivermos inseridos em grupos sociais organizados pelos marcos sociais coletivos da memória, não está totalmente descartado por Candau, uma vez que se posiciona em relação a essa visão pautando que os marcos sociais coletivos seriam mais plausíveis do que o termo memória coletiva, já que para formarmos uma imagem de nossas lembranças mais completa.

Podemos recorrer ao auxílio da memória de outros sujeitos, todavia, esse exercício de reconstruir uma lembrança do passado irá de certa forma utilizar os marcos sociais coletivos da memória, principalmente no tocante a representação dos signos, com o uso da linguagem que é uma construção social, onde uma expressão pode ser ferramenta de evocação e interpretação de lembranças.

Nesse caso, mesmo ao utilizarmos os marcos sociais da memória, não significa que a memória seja totalmente coletiva ou individual, já que não seria possível, logo os marcos sociais da memória estão presentes na memória individual. Nessa medida, a memória como aptidão humana individual, sofre influências dos marcos sociais, que auxiliam no esclarecimento, na reconstrução e na evocação das lembranças (CANDAU, 2011). 
Nesse sentido, Candau discorda dessa visão de Halbwachs, de deixar a memória individual como passiva aos efeitos do coletivo, já que somos sujeitos sociais. Fazemos partes de grupos, mas nossas memorias não são meramente coletivas, pois nessa visão as memorias pessoais, as ações, os pensamentos e devaneios seriam apenas obras de uma ação da sociedade sobre o indivíduo.

Principalmente se nos deixarmos levar pelas ações memoriais ditas coletivas de instituições como museus, de discursos coletivos, de narrações e de metáforas. A ideia de consenso comum nos faz cair em uma armadilha em que todos os grupos que possuam similitude para se expressarem, como mesma linguagem ou mesma religião construiriam uma mesma representação do passado que seria compartilhada por todos.

No entanto, não há como se comprovar que esses sujeitos expressaram as lembranças do passado da mesma forma, que a apropriação e rememoração desse, ou que vão gerar uma representação comum a todos, não há como mensura o que é relembrado. Por mais que os sujeitos acreditem na ideia de que os outros lembram e compartilham da sua mesma memória.

Sendo assim, a memória é a ação humana capaz de evocar experiências vividas no passado e traz alguns elementos dessa à tona no presente, em um jogo de ilusão. Seria possível ter esse passado de volta, de reaviva-lo, de certa maneira fragmentos desse passado tornam-se possíveis de serem acessados através das lembranças.

Bergson e Candau compreendem a memória a partir de uma perspectiva individual, considerando os fenômenos da memória com relação ao indivíduo e a suas recordações, pautando-se pelas representações que cada um faz do passado, ainda que elementos externos (os marcos sociais) sejam evocados para a construção das memórias do sujeito.

Com isso, Ricoeur (2007) ressalta que não recordamos apenas das representações de nós mesmo, mas de nossas relações de vivência com o mundo, das experiências com o outro e com o contexto. As minhas memórias não ficam pressas apenas a Mim, a minha imagem, não vejo apenas Eu em minhas lembranças, seja praticando alguma ação ou aprendendo algo, mas sim observo situações de mundo e de mundos ao qual participo e pratico ações.

Considerando a polaridade do corpo reflexivo e do corpo da mundanidade, do meu eu interior com o meu exterior construindo experiências que iram gerar recordações com Outros, do próprio reconhecimento da minha identidade perante mundo (RICOEUR, 2007). Já a memória coletiva, Halbwachs (1990) apresenta essa no sentido de que nos apoiamos nas lembranças do outro. A confiança será maior quando há esse apoio recíproco entre lembranças, principalmente na função de evocar a memória que é coletiva. Uma vez que, só 
lembramos pelo outro, mesmo quando se trata de acontecimentos nos quais só Eu estive envolvido, com objetos que só Eu vi.

$\mathrm{Na}$ verdade, nunca estamos sós, mesmo sem a presença física de alguém, pois em mim carrego sempre os elementos sociais, as referências e as ideias dos outros. Com isso, as lembranças individuais que vivo não são apenas minhas, já que utilizarei referências sociais para me guiar no que estou vivendo, seja por meio da história ou por relatos, as impressões que carrego em mim se baseiam e se criam coletivamente (HALBWACHS,1990).

Assim, segundo o autor para que as memórias sejam auxiliadas por outras memórias, é necessário que essas tenham pontos de concordância e identificação comum. A possibilidade de reconstituirmos e recordamos uma lembrança que está a muito tempo no passado é uma tarefa árdua, se não fizermos mais parte do grupo, pois já não existe mais interesse e trocas de dados, não existe mais elementos de coesão, não recordo mais do que foi vivido em comum com essas pessoas que outrora compartilhava lembranças.

Como afirma Halbwachs, pertenço a outros grupos e realidade, ou seja, são as noções comuns que o Eu e o Outro do grupo partilhamos, que torna possível as lembranças coletivas serem reconstruídas, evocadas e compreendidas. Dessa forma, quando estamos em uma situação de isolamento e surge uma lembrança ou imagem que não se associa a nenhum grupo, que não se apoia em minhas referências sociais, que pertence apenas a mim, nesse caso, a memória coletiva não interpreta todas as nossas lembranças.

Porém, pertencemos a grupos sociais, absorvemos e criamos imagens e conceitos coletivos, possibilitando que esses se interponham na lembrança individual, sem que ocorra a percepção dessa ação, tendo nas lembranças "um estado de consciência puramente individual" (p.24). Uma intuição sensível, ou seja, uma memória individual não é isolada de influências externas, porque, para lembrar de meu passado utilizo os mecanismos de referência. Como a linguagem que são criações sociais, externas a mim.

A memória coletiva está sempre em uma continuidade, o indivíduo lembra, retém do passado somente aquilo que permanece na consciência do grupo, suportes dessa no tempo e no espaço, possui duração ligada aos membros do grupo. De tal maneira, não existem meios de "guardar" todas as lembranças em suas matizes e formas, do contrário acessaríamos essas sempre que desejássemos, podemos evoca-las mais nitidamente com o apoio dos suportes da memória coletiva (HALBWACHS, 1990). 


\section{Passado e Presente}

Todavia as chamadas memória pura ou memória verdadeira, para Henri Bergson em é a memória que registra e representa o passado em sua exatidão, todos os detalhes vividos sem deixar escapar nenhum detalhe. Preservando aquela imagem completa. Nesse sentido é uma memória do espírito, sendo que apenas algumas imagens desse passado serão acessadas pela consciência, pois resultaria impossível as ações da consciência se esse passado completo viesse à tona simultaneamente com o presente.

Logo, o cérebro tem como tarefa impedir que a memória pura envolva completamente a consciência, permitindo apenas fragmentos de lembranças que consigam responder as demandas e ações evocadas. A memória pura é espiritual mais algumas de suas lembranças são filtradas pelo cérebro, está localizada além da consciência. Como afirma Bergson (1999, p.177) "co-extensiva à consciência, ela retém e alinha uns após outros todos os nossos estados à medida que eles se produzem, dando a cada fato seu lugar e consequentemente marcandolhe a data, movendo-se efetivamente no passado definitivo".

Podendo ser acessada através do sonho e do estado de devaneio, nesse mundo onírico que não é poluído e tocado pela esfera material (sociedade). Dessa forma, o passado se conserva como um todo, não passa, nossos anseios, lembranças, ações e representações desse se mantem intocadas. Como se estivesse envolto em um véu impermeável as ações do tempo e do espaço, intangível a matéria, tangível apenas ao espírito (BERGSON, 1999). Como exemplo: lembranças da infância principalmente nas idades iniciais.

Em seguida, a memória tida como hábito que Bergson nos apresenta, são as repetições do passado. Praticadas em movimentos mecânicos automáticos que não necessitam ser evocados em um exercício forçado de reflexões mentais do passado. A memória hábito age no corpo, ou seja, são aprendidas, como movimentos voluntários como o comer, beber, escrever, dirigir, falar, caminhar, gesticular "num sistema fechado de movimentos automáticos que se sucedem na mesma ordem e ocupam o mesmo tempo" (p.86).

Seguindo a linha de pensamento do autor precitado, a memória hábito corresponde a uma resposta a demanda da sociedade e da cultura, em um processo de aprendizado que ocorre até ser fixado e transformado em algo cotidiano. Logo, para o autor a memória tem como função primordial guardar o passado, para que esse esteja vivo sendo evocado ao presente através das lembranças. Já que o presente conduz a ação e o passado é estático, mas mantendo-se ativo no espirito, entendido como o inconsciente. A lembrança é que nos permite percebe que o passado ainda existe e se conserva, pois em todo espírito o passado sobrevive e todo homem tem espirito. A consciência nos possibilita exteriorizar esse passado por meio das 
representações de imagens/lembranças, porém só se mantém puro no espirito, onde todas nossas recordações psíquicas estão seguras e preservadas.

Sendo que, ele buscou refletir sobre um passado que se conserva em sua totalidade no espiritual, em memórias puras que não se desprende de si mesmas. Intangíveis na materialidade, que só podem ser acessadas em sonho no mundo em que o espirito está livre. É através das lembranças que o passado existe, para tanto, não leva em consideração os elementos sociais e culturais dos sujeitos, como se esses não interferissem nas memórias, como se elementos externos não impulsionassem o passado (BOSI, 2001).

De acordo com Bosi, Bergson não levou em consideração em suas discussões sobre a memória, o sujeito que realiza a ação de lembrar e muito menos a troca que ocorre entre sujeito e objetos que evocam lembranças, como do sujeito com o seu contexto. Em contrapartida Maurice Halbwachs (2004), argumenta que as memórias são construídas coletivamente, que os quadros sociais da memória como a família, a religião e as classes socais, são mecanismos localizadores das memórias, servem como arcabouço dessas. Nenhum sujeito tem a aptidão de lembrar sem estar inserido no espaço social.

A memória não seria apenas uma retransmissão de fatos do passado, ao contrário, busca reconstruir imagens desse através de ideias do presente, é um conjunto de imagens e ações vividas no passado que são relembradas coletivamente. A memória não é efêmera ela exerce a função de lembrar (HALBWACHS, 2004). Uma imagem de uma lembrança a muito tempo vivida por mais visível que esteja com todos os seus contornos, ao ser lembrada ela não será a mesma de antigamente quando de fato se formou, porque não somos mais a mesma pessoa. Nossos valores e percepções de mundo se transformaram. O próprio tempo muda já que estamos lembrando o passado no presente.

Com isso, Bosi ressalta que para o passado se conservar totalmente, no sentido de Bergson, seria preciso que o sujeito já em fase de vida adulta se conservasse. Em um meio que não houvesse qualquer forma de alteração de seus hábitos, representações, signos, relações familiares e sociais de quando era apenas uma criança. Algo inviável já que a memória está inserida no meio cultural, que não se estagna. Em relação ao sonho que mantém o passado intacto, na visão de Bergson, Halbwachs (2004) ressalta que mesmo em sonho o presente atua, uma vez que não nos desprendemos desse eu modificado pelo tempo presente. Essa ilusão de que o sonho não está sendo influenciado ocorre pela falta da ação da consciência nesse. Tomando de exemplo a imagem de um cavalo correndo em meio a um prado esverdeado, a qualquer momento esse pode alçar voo, porém cavalos não voam. 
Utilizando elemento de identificação coletiva para firma, interpretar e criar imagens de representação no sonho, que se encontram perdidas e desconectadas, mas que estão fortemente relacionadas com situações vividas pelo sujeito em meio a seus grupos coletivos. Então as imagens do cotidiano, sem utilizar dos marcos sociais, se mantem mesmo em estado de inconsciência.

Enquanto para Bergson o passado se mantém, para Halbwachs ele não conserva, apenas temos representações desse, não há como mantê-lo completamente. No entanto, ambos autores abdicam da ideia de que a memória é apenas metafisica que pode ser mensurada e compreendida através de investigações laboratoriais. Criticando-se então a ciência da psicologia que busca definir a memória por meio de estímulos físicos do corpo, em suma encontra-se em ambos a ideia de imagem que compõem o passado e da relação com o tempo e da duração desse.

Dessa forma, percebemos que a linha entre passado e presente é ínfima, ao criarmos um conjunto de imagens que contemplam e conectam os dois tempos. Nesse sentido vale ressaltar a tradição com suas fortes memórias organizadas em relação contínua com o passado e as identidades e memórias construídas. se baseia em elementos comuns de compartilhamento para se fixarem.

\section{Compartilhamento do Comum}

Como argumenta Ricoeur (2007) a memória tem como múnus a lembrança, em um ato de coerção subjetiva a nós, em um laço emocional e social do direito que o outro possui de não ser esquecido. Em um movimento de compartilhamento, em que não recordamos apenas das representações de nós mesmo, mas de nossas relações de vivência com o mundo, das experiências com o outro e com o contexto. As minhas memórias não ficam pressas apenas a Mim, a minha imagem, uma vez que, não vejo apenas o Eu em minhas lembranças, seja praticando alguma ação ou aprendendo algo, mas sim observo situações de mundo e de mundos ao qual participo e pratico ações.

À vista disso, a memória com o seu dever de partilhar as lembranças do outro que não eu, possibilita que as tradições orais tenham como finalidade a criação e o partilhamento de elementos memorizantes em processo constante de atualização. Posto que, essas não aludem apenas parcelas de informações descontruídas e esfaceladas. Visto que, as tradições orais adotam a novos fundamentos e adaptam esses as necessidades dos sujeitos e seus grupos (PRINS, 1992), em uma ação que envolve o eu e o meio. 
Nesse seguimento, segundo Arévalo (2004) as coletividades desenvolvem e reinterpretam suas tradições de acordo com suas necessidades e o cotidiano do meio ao qual estão inseridos. Por conseguinte, a tradição, como o passado rememorado no presente, relaciona-se diretamente a construção da identidade coletiva cultural. A identidade moldada na sociedade, e calcada na diferença, da alteridade entre o eu e o outro.

Com efeito, de acordo com Peralta (2007) o trabalho da memória, além do duo lembrar/esquecer, é o da construção da identidade, solidificando valores e significações, que estabeleceram fatores comuns e diferentes de um grupo. Com isso, a memória considerada coletivamente é o arcabouço de fixação da identidade compartilhada pelos sujeitos e seus grupos sociais, permitindo assim sua existência em um contexto-tempo.

Nessa linha de argumentação, Candau (2011) apresenta a definição dos sóciotransmissores, através dos sujeitos que possuem como função em um grupo, de transmitir o saber comum a todos da comunidade. Ressaltando, o fato de que as narrações são variáveis de acordo com o narrador, ou seja, elas são percebidas e compartilhadas de diferentes percepções e compreensão, o testemunho de uma mesma ação será diferente para cada observador. Em consequência, das funções cerebrais dos seres humanos que são únicas em cada indivíduo. As experiências vivenciadas, e até mesmo compartilhadas por atores sociais, pôr mais que apresentem fatores comuns, serão sempre interpretadas e reinterpretadas por diferentes configurações.

Para o autor os sócio-transmissores operam como executores da protomemória ${ }^{2}$, emissores de uma memória de alto nível ${ }^{3}$ e como propulsores da metamemoria ${ }^{4}$. Possuem como dever, serem encarregados pelas atuações dos sujeitos sociais que instituem uma rede entre psiques, por meio de conhecimentos, de símbolos, de valores sociais e culturais. Estabelecendo assim as conexões entre memórias.

Nessa perspectiva, os sóciotransmissores são atuantes ativos da narração de memórias e no seu compartilhamento, como na guasquería com elementos de saber-fazer que são transmitidos, por diferentes recursos e técnicas, em uma construção de uma narrativa pessoal

\footnotetext{
${ }^{2}$ Protomemória, memórias que se manifestam automaticamente, que não exigem um exercício forte de evocação são: os hábitos, os gestos e a linguagem corporal/oral/escrita, em que não precisa realizar-se uma reflexão analítica, é automática, o passado apropriasse do corpo como local de ação (CANDAU, 2011).

${ }^{3}$ Memória de alto nível ou memória de lembranças (ou de reconhecimento), que incorpora vivências, saberes, crenças, sentimentos e sensações, podendo contar com extensões artificiais ou suportes de memória (CANDAU, 2011).

${ }^{4}$ A metamemória, ou seja, tanto a representação que cada indivíduo faz de sua própria memória, quanto aquilo que fala sobre ela, em uma dinâmica de ligação entre o indivíduo e seu passado, como uma memória reivindicada (CANDAU, 2011).
} 
que envolve a troca de experiências entre narrador e ouvinte/aprendiz, em uma ligação de sensibilidade, sendo os lócus da memória as sensações (CANDAU, 2011).

Em meio as trocas de conhecimento que ocorrem entre sujeitos, devem se considerar a perspectiva de Rancière (2005) da existência de um comum sensível compartilhado em que "a partilha da sensível faz ver quem pode tomar parte no comum em função daquilo que faz, do tempo e do espaço em que essa atividade se exerce. Assim, ter essa ou aquela "ocupação" define competências ou incompetências para o comum, dotado de uma palavra comum" (p. 16)

Nessa linha de visão, a concepção de um compartilhamento sensível do autor precitado, de um comum sensível no espaço-tempo e no mundo simbólico, possibilita que o comum seja observado em sua singularidade. O mesmo não deve ser posicionado em uma visão generalizada de homogeneidade coletiva identitárias, pois, o comum não é genuíno, mas algo criado. Assim, temos a existência de um comum (culturas, liberdade, direitos humanos, direitos civis e outros) e também fragmentos que desse comum consolidam diferentes locais e dimensões de disputas plurais.

Logo, retomamos aos sóciotransmissores em que essas conexões do comum, são necessárias para o compartilhamento memorial. Novamente, os sóciotransmissores podem ser compreendidos como os condutores da comunicação sociocultural e da participação do sujeito social em uma regulamentação de atuação da rememoração coletiva e sua manifestação. Como exemplo a tradição que utiliza dos sóciotransmissores no ato das evocações dos símbolos que a representam, na materialização de suas experiências.

Em relação a concepção do compartilhamento de conhecimento, para Bartol e Srivastava (2002) essa ação pode ser compreendida como a partilha de ideias, noções, conceitos, signos e experiências coerentes e fortemente organizadas do indivíduo com sua coletividade. Sendo, um processo continuo, não é apenas a ação de um indivíduo transmitir o que conhece para outro, não é algo linear. Visto que, temos a relação do transmissor e receptor, e também, do meio que influência na forma que esse conhecimento será absorvido.

Retomamos ao fato de que para que ocorra um compartilhamento de saber-fazer deve se estruturar elementos de comunicação comum entre os sujeitos. Pois, sem compreende-los poderíamos reinterpretar de forma equivocada a mensagem dita. Sendo que, "o significado que uma pessoa expressa nunca é o mesmo que aquele gerado na mente da pessoa que o recebe" (SVEIBY, p. 49; 1998). O emissor também pode não conseguir transmitir seu conhecimento, por falta de significantes que representem o que deseja compartilhar. 
Portanto, a transmissão de fatos do passado em certo ponto, para que seja possível seu compartilhamento, deve se estabelecer elementos comuns aos sujeitos dos grupos, uma memória forte, como no caso da tradição, um mecanismo de transmissão, que possibilita que elementos comuns fortemente organizados em estruturas socioculturais sólidas possam ser memorizados e assim compartilhados por muito tempo, no qual, a dualidade do lembrar e do esquecer permite as ações das tradições e sua existência.

\section{Referências}

ARÉVALO,Javier Marcos. La tradición, el patrimonio y la identidad, 2004. Disponível em:http://www.dipbadajoz.es/publicaciones/reex/rcex_3_2004/estudios_02_rcex_3_2004.pdf BARTOL, K., SRIVASTAVA, A. (2002, Summer). Encouraging knowledge sharing: the role of organizational reward systems. Journal of Leadership \& Organizational Studies, 9(1), 6476

BERGSON, Henri. Matéria e Memória. Ensaio sobre a relação do corpo com o espírito. SP: Martins Fontes, 1990.

BOSI, Ecléia. Memória e Sociedade: Lembrança de velhos. SP: Companhia das Letras, 1985. CANDAU, Joel. Memória e Identidade. São Paulo: Contexto, 2001.

CANDAU, Joel. Memória e identidade. Tradução: Maria Leticia Ferreira. São Paulo: Contexto, 2011.

HALBWACHS, Maurice. A Memória Coletiva. São Paulo: Ed. Centauro, 1990.

Los marcos sociales de la memoria. Caracas: Anthropos Editorial, 2004.

PERALTA, Elsa. Abordagens teóricas ao estudo da memória social: uma resenha critica; in: Arquivos da Memória: Antropologia, Escala e Memória, $n^{\circ} 02$ (Nova Série). Portugal: Centro de Estudos de Etnografia Portuguesa 200, p. 4-23. 2007.

RANCIÈRE, J. (2005a). A partilha do sensível: estética e política. São Paulo: EXO/34.

RICOEUR, Paul. A memória, a história, o esquecimento. Campinas, SP: Unicamp, 2007.

SVEIBY, K. E. A nova riqueza das organizações (L. E. T. Frazão, Trad.). Rio de Janeiro: Campus. (1998). 